\title{
Rheological Studies of Aqueous Stabilised Nano-zirconia Particle Suspensions
}

\author{
Asad Ullah Khan*, Anwar Ul Haq, Nasir Mahmood, Zulfiqar Ali
}

\author{
Department of Chemical Engineering, COMSATS Institute of Information Technology, \\ Defence Road, Off Raiwind Road, 54000 Lahore, Pakistan
}

Received: February 5, 2011; Revised: October 25, 2011

\begin{abstract}
In the present investigation aqueous suspensions of nano- and colloidal range particles are stabilised by changing the ambient $\mathrm{pH}$. Rheology is used to establish the stability of the suspensions and it is found that the rheology of the suspensions is strongly dependent on the $\mathrm{pH}$ values. The viscosity is highest close to the iso-electric point of the powders. At the iso-electric point the net surface charge on the powder particles is zero and is the cause of the high viscosity. Away from the iso-electric point, the particles are charged, giving rise to a double layer phenomenon and causing the reduction in viscosity. It is also found that increasing the solid contents of the suspensions reduces the $\mathrm{pH}$ region of low viscosity.
\end{abstract}

Keywords: zirconia, rheology, electrophoretic mobility, suspension

\section{Introduction}

Ceramic materials are widely used as high-tech structural materials for their excellent mechanical properties. These materials have been a part of many investigation studies to improve the properties for their extended applications. In this series Zirconia is one of the special type of ceramic material which found applications as an advanced structural material for their excellent mechanical properties ${ }^{1,2}$. To broaden its utility, it is highly demanded to obtain a fine grain microstructure and to fabricate components with complex shapes. This can be achieved by using ultra-fine powders combined with forming by colloidal processing ${ }^{3}$. The colloidal processing techniques such as direct coagulation, gel, slip, tape and centrifugal casting ${ }^{4-8}$, are required to have the slurries with good dispersion and desirable rheological behaviour for enhancing the green body density and final sintering properties ${ }^{9,10}$. During processing the nano and colloidal range ceramic particles usually spontaneously aggregate in the dispersing medium due to the relatively high strength of the inter-particle van der Waals attractive forces. It is desired to control the strength of these attractive forces in order to impart a resistance against aggregation. In practice, the stability against aggregation is achieved by introducing a repulsive force barrier between the particles. This repulsive barrier can be achieved by two generic mechanisms: (i) Electrostatic stabilisation and (ii) steric stabilisation $^{11-15}$

DLVO theory relates the particle-particle interaction as a function of separation between particles. When the electric charge on the particles is low in a suspension, strong attractions between the particles exist and as a result the viscosity or the yield stress is high ${ }^{16-20}$. This higher viscosity or yield stress value is due to the fact that at lower electrical charges the mobility of the particles is restricted; giving rise

*e-mail: asadkhan@ ciitlahore.edu.pk to the higher viscosity or yield stress values. The magnitude of the particle-particle interaction for two particles is related to the surface potential or zeta-potential (electrophoretic mobility) and the size of the particles ${ }^{21}$.

Metal oxides particles e.g. zirconia powders (and many other ceramic powders as well) may become electrically charged, depending upon the $\mathrm{pH}$ of the aqueous suspending medium, due to the adsorption of dispersant molecules which contain the ionisable ions or the dissociation/ association of surface hydroxyl group with $\mathrm{H}^{+} / \mathrm{OH}^{-}$ions ${ }^{22-25}$. When the $\mathrm{pH}$ of the suspension is at or close to the isoelectric point (iep) i.e. the $\mathrm{pH}$ at which positive sites and negative sites on the particle are equal, the particles tend to aggregate as there is hardly any repulsion between them. The tendency of the aggregation causes an increase in the viscosity. This effect can be overcome by changing the $\mathrm{pH}$ away from the iep, that make the particles charged by the following chemical reactions ${ }^{23,26,27}$.

$\mathrm{OH}^{-}+\mathrm{MOH} \rightarrow \mathrm{MO}^{-}+\mathrm{HOH}$

$\mathrm{MOH}+\mathrm{H}^{+} \rightarrow \mathrm{MOH}_{2}^{+}$

where $\mathrm{MOH}$ corresponds to the metal oxide surface hydroxyl group.

The relationship between the particle charge caused by the change in the $\mathrm{pH}$ values and the viscosity of the suspension is studied in this investigation. The results are explained in the light of electrostatic stabilization mechanism explained above. The zirconia suspensions (slips) investigated here are suitable for slip casting and drain casting techniques. These techniques produce green ceramic compacts of high green density. On sintering, the green compacts are converted to final ceramic product. Three different zircona powders having different surface areas 
and iso-electric points are investigated. Two of the powders studied have the same doping concentration of yitria but their surface areas are different. The effect of the surface area on the rheology of the system studies is highlighted.

\section{Experimental}

\subsection{Material}

Three kinds of zirconia powder were used. Their bulk chemical compositions were non-doped zirconia and 3 mole percent yttria doped zirconia (two samples). The details of three zirconia powders are given in Table 1 . The particle sizes $\mathrm{D}_{10}, \mathrm{D}_{50}$ and $\mathrm{D}_{90}$ donate the diameters of the particles which constitutes 10,50 and 90 percent by volume, respectively. The ratios of $\mathrm{D}_{10}, \mathrm{D}_{50}$ and $\mathrm{D}_{90}$ are the measure of polydispersity.

The water used in all the experiments for preparing different suspensions/samples, was taken from a Purite (Purite Ltd., Oxon, England) water purifying unit. The equipment uses a combination of deionisation and reverse osmosis processes.

\subsection{Rheological and electrophoretic mobility measurements}

A Bohlin VOR rheometer (Bohlin Rheologi, Lund, Sweden) was used for the rheological studies of the suspensions which were dispersed using a ultrasonic probe; Vibra-Cell VCX 600 (Sonic and Materials, Connecticut, USA). The electrophoretic mobility experiments of the very dilute suspensions was carried out using a Zeta Master (version PCS, Malvern Instruments, UK) microelectrophoresis instrument. The average mobility reported in this paper was taken from the mean of at least 15 different experimental runs.

For the electrophoresis (electrophoretic mobility) experiments, stock suspensions containing ca. $1 \%(\mathrm{w} / \mathrm{v})$ particles were prepared in 10-3 $\mathrm{M} \mathrm{KNO}_{3}$ solution. The suspensions were ultrasonicated with a Vibra-Cell VCX 600 ultrasonicator. A few drops of the stock suspension were used to make several more dilute suspensions ( $30 \mathrm{~mL}$ in volume) in a known $\mathrm{KNO}_{3}$ electrolyte concentration (10-3 M). The $\mathrm{pH}$ values of the suspensions were adjusted and stored overnight. Prior to the electrophoresis experiments, the $\mathrm{pH}$ of the suspensions was noted again. For the suspensions in which $\mathrm{pH}$ values were changed the solid contents were $30 \%$ by weight. $30 \% \mathrm{wt} / \mathrm{wt}$ suspensions were chosen as the most suitable with respect to ease of the change of $\mathrm{pH}$ and reasonable rheological response.
For the rheological experiments at the natural $\mathrm{pH}$ values, first highest solid fraction samples of the three zirconia powders were prepared by using the following procedure. The required amount of the powder and distilled water was added in a $60 \mathrm{~mL}$ jar. The volume of the suspensions was $50 \mathrm{~mL}$. The suspensions were ultrasonicated continuously for two minutes by using a Vibra-Cell VCX 600 ultrasonicator. During the ultrasonication, the samples were placed in an ice cooled water to avoid over-heating. The lower solid content samples at the natural $\mathrm{pH}$ values were made by diluting the above samples. The diluted samples were ultrasonicated again for 1.5 minutes to re-disperse the particles using the above procedure.

For the rheological experiments in which $\mathrm{pH}$ values were varied, for each $\mathrm{pH}$ value and solid fraction, new samples were prepared. A fixed amount of $\mathrm{HNO}_{3}$ (acid) or $\mathrm{NaOH}$ (base) and water was added in the sample jar, followed by the addition of zirconia powder. The samples were placed on a shaker for about two hours. Then the samples were left standstill overnight. These samples were then ultrasonicated for 2 minutes and rested for 30 minutes before being tested for rheology. Just before the rheological experiments, the $\mathrm{pH}$ values were noted.

Before performing the rheological characterisation, the samples were pre-sheared at a very high shear rate of 960/s for $\mathrm{ca}$. 3-4 minutes followed by at least a 2 minutes rest period in order to provide a common and consistent shear history for the systems. The viscosity at low shear rates was measured first, stepping up to higher shear rates, covering the shear rate range of $10^{-1}$ to $10^{3} / \mathrm{s}$. The results reported here for the selected shear rates were taken from the above shear rate range experiments. All the experiments were performed at $25^{\circ} \mathrm{C}$.

\section{Results and Discussion}

\subsection{Electrophoresis}

Figure 1 shows the electrophoretic mobility in a $10^{-3} \mathrm{M}$ $\mathrm{KNO}_{3}$ solution of the three sample of zirconia coded as $\mathrm{Y}_{3}$, $\mathrm{Y}_{3} \mathrm{U}$ and $\mathrm{ZrO}_{2}$. The $\mathrm{pH}$ of the iep values of these samples were $6.8,5.4$ and 7.5, respectively. It can be seen from this figure that the electrophoretic mobility behaviour is quite different for each case. At $\mathrm{pH}$ values lower than the iep there is a net positive charge and at $\mathrm{pH}$ values higher than iep there is a net negative charge. The cause of the net negative and/ or positive charges is represented by Equations 1 and 2. The strength of net positive and negative charge depends on the prevailing $\mathrm{pH}$ of the system. This difference in the above behaviour of the three systems indicates that the surface

Table 1. Characteristics of the zirconia powders.

\begin{tabular}{cccccccc}
\hline $\begin{array}{c}\text { Zirconia } \\
\text { powder }\end{array}$ & Code & $\begin{array}{c}\text { Doping } \\
\text { component }\end{array}$ & $\begin{array}{c}\text { BET surface } \\
\text { area }\left(\mathbf{m}^{\mathbf{2}} \mathbf{g}^{-1}\right)\end{array}$ & Supplier & \multicolumn{3}{c}{ Particle size $(\boldsymbol{\mu m})$} \\
\cline { 6 - 9 } & & & & $\mathbf{D}_{\mathbf{1 0}}$ & $\mathbf{D}_{\mathbf{5 0}}$ & $\mathbf{D}_{\mathbf{9 0}}$ \\
\hline Non-doped zirconia & $\mathrm{ZrO}_{2}$ & none & 22.50 & Zirconia sales, UK & $0.048 \pm 0.002$ & $0.14 \pm 0.01$ & $0.32 \pm 0.03$ \\
Doped zirconia & $\mathrm{Y}_{3}$ & 3 mole $\% \mathrm{Y}_{2} \mathrm{O}_{3}$ & 7.43 & Zirconia sales, UK & $0.30 \pm 0.02$ & $0.71 \pm 0.03$ & $1.26 \pm 0.05$ \\
Doped zirconia & $\mathrm{Y}_{3} \mathrm{U}$ & 3 mole $\% \mathrm{Y}_{2} \mathrm{O}_{3}$ & 17.91 & Zirconia sales, UK & $0.051 \pm 0.003$ & $0.16 \pm 0.01$ & $0.39 \pm 0.03$ \\
\hline
\end{tabular}




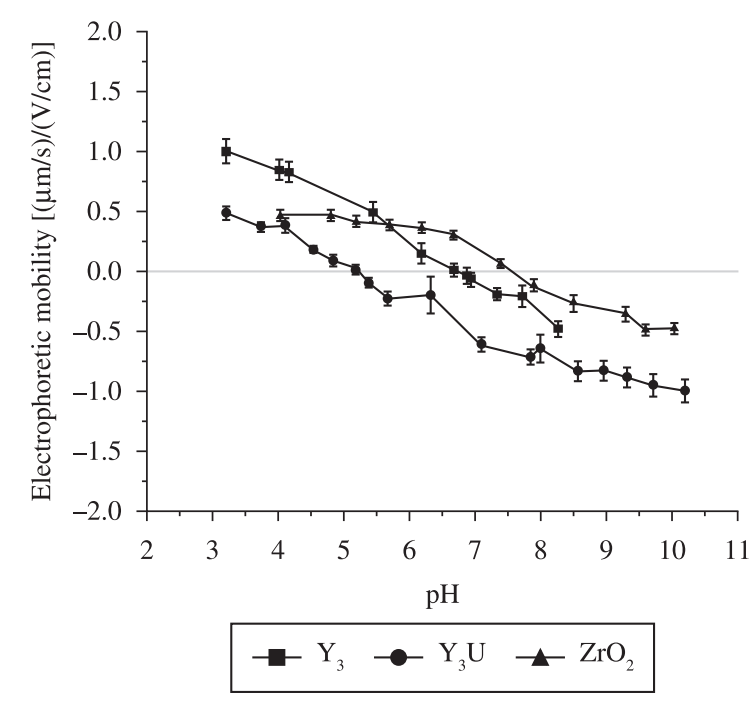

Figure 1. Electrophoretic mobility of three different zirconia, powders $\left(\mathrm{Y}_{3}, \mathrm{Y}_{3} \mathrm{U}\right.$ and $\left.\mathrm{ZrO}_{2}\right)$ as a function of $\mathrm{pH}$.

physical and chemical properties of these three powders used are different. The surface physical and chemical properties also affect the rheological behaviour of the suspensions.

\subsection{Rheology}

In the following sections the effect of particle surface charge and surface area on the rheology of the various zirconia suspensions is discussed. The change in the ambient $\mathrm{pH}$ of the suspensions modifies the charge on the particles. The addition of an acid/base to the suspension reacts with the hydroxyl group present on the surface of the zirconia powder, and thereby changing the surface charge density. The change in the surface charge density of the particles in a suspension affects the rheology of the suspension.

\subsubsection{Powder concentration effect}

In Figure 2, the viscosities at a shear rate of 146/s for the three different zirconia powder suspensions as a function of the solid concentration (Krieger-Dougherty type relationship), are shown. All the suspensions were at their natural $\mathrm{pH}$ i.e. without any acid/base addition and these $\mathrm{pH}$ values were 7.1, 8.1 and 7.9 for $\mathrm{Y}_{3} \mathrm{U}, \mathrm{Y}_{3}$ and $\mathrm{ZrO}_{2}$, respectively. For all the samples the viscosity increased as the solid content was increased. The increase in the viscosity behaviour, with the increase of solid concentration, is clearly different for all the three zirconia powders used. The $\mathrm{Y}_{3} \mathrm{U}$ suspensions show the smallest rate of increase in the viscosity. This relatively low viscosity change, compared to the viscosity change of the other zirconia suspensions, may be attributed to the high surface charge (negative) at the natural $\mathrm{pH}(=7.1)$ (Figure 1) of the suspensions. When the surface charge is high, the aggregation is relatively low due to the electrostatic repulsion. The greatest rate of increase in the viscosity with the increase of the solid content is found for the $\mathrm{ZrO}_{2}$ suspensions and this may be attributed to two factors; a rather high surface area for the $\mathrm{ZrO}_{2}$ and a natural $\mathrm{pH}$ close to the iep, where the $\mathrm{ZrO}_{2}$ particles have a rather

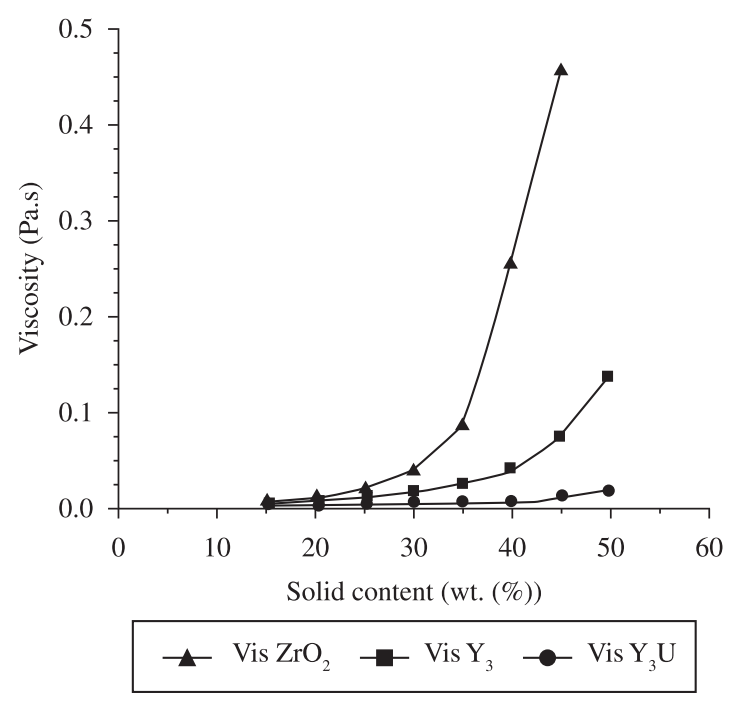

Figure 2. Viscosity as a function of solid content at a shear rate of 146 /s for three different zirconia powders $\left(\mathrm{Y}_{3}, \mathrm{Y}_{3} \mathrm{U}\right.$ and $\left.\mathrm{ZrO}_{2}\right)$.

low surface charge. There is a very weak repulsion when the surface charge on the particles is low, so they can come close to each other and thus aggregate. The $\mathrm{Y}_{3}$ suspensions have a lower viscosity compared with the $\mathrm{ZrO}_{2}$ suspensions because of the relatively low surface area of the $\mathrm{Y}_{3}$ particles. From the comparison of the $\mathrm{ZrO}_{2}$ and $\mathrm{Y}_{3} \mathrm{U}$ suspensions $\left(\mathrm{ZrO}_{2}\right.$ and $\mathrm{Y}_{3} \mathrm{U}$ have similar surface areas, Table 1) it appears that the surface chemistry (surface charge) has the more dominant influence upon the rheology than the size of the powder particles. The difference at the natural $\mathrm{pH}$ and the iep for $\mathrm{ZrO}_{2}$ and $\mathrm{Y}_{3} \mathrm{U}$ is 0.4 and 1.7, respectively. Also, the electrophoretice mobility of $\mathrm{Y}_{3} \mathrm{U}$ at its natural $\mathrm{pH}$ (5.4) value is significantly higher the electrophoretice mobility of $\mathrm{ZrO}_{2}$ at its natural $\mathrm{pH}$ (7.5). In other words the surface charge on $\mathrm{Y}_{3} \mathrm{U}$ zirconia particles is much higher than the surface charge on $\mathrm{ZrO}_{2}$ particles. Therefore, the double layer repulsion in the $\mathrm{Y}_{3} \mathrm{U}$ suspensions will be stronger than that of the $\mathrm{ZrO}_{2}$ suspensions at their natural $\mathrm{pH}$ values and consequently the viscosity of the $\mathrm{Y}_{3} \mathrm{U}$ suspensions is lower than the corresponding $\mathrm{ZrO}_{2}$ suspensions. The degree of the polydispersity of these two powders is quite comparable.

\subsubsection{Effect of $\mathrm{pH}$}

Figure 3 shows the viscosity of zirconia $\mathrm{Y}_{3} \mathrm{U} 30 \% \mathrm{wt} / \mathrm{wt}$ suspensions at three different shear rates. The natural $\mathrm{pH}$, the $\mathrm{pH}$ without adjustment by acid or base, was found to be 7.1. At the natural $\mathrm{pH}$ and above the suspension is well stabilised and has a low viscosity. At $\mathrm{pH}$ values less than 7.0 the viscosity of the suspension increases. This increase in the viscosity is due to the lower surface charge on the particles at these $\mathrm{pH}$ values as compared to the surface charges at $\mathrm{pH}$ values 7.0 and more. The maximum viscosity is observed at $\mathrm{pH} 4.1$ which is quite close to the iso-electric point (iep) of the zirconia $\mathrm{Y}_{3} \mathrm{U}(\mathrm{pH}$ 5.4). At $\mathrm{pH}$ values less than 4.0 the viscosity starts decreasing again. However, in the acidic $\mathrm{pH}$ range investigated, the viscosity is significantly higher than under basic conditions; that is for $\mathrm{pH}$ values of more than 


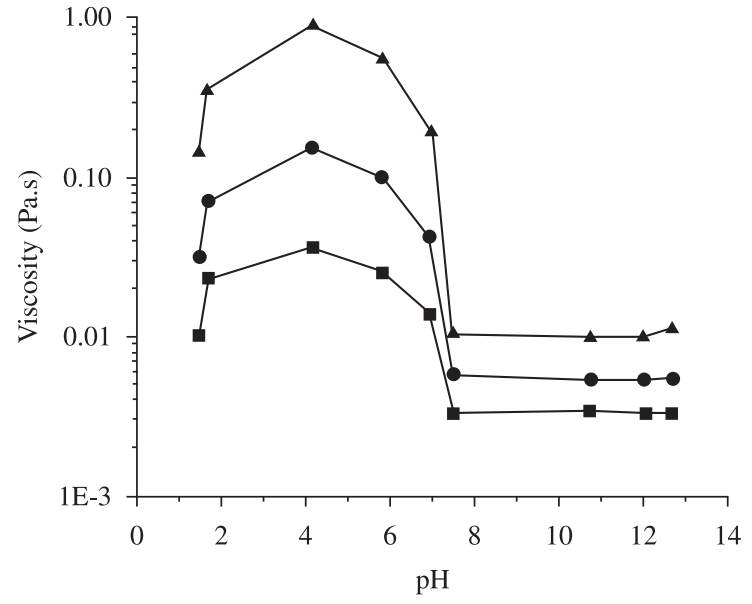

- SR $146 / \mathrm{s}$ SR $14.6 / \mathrm{s} \rightarrow$ SR $1.46 / \mathrm{s}$

Figure 3. Viscosity as a function of $\mathrm{pH}$ of zirconia $\mathrm{Y}_{3} \mathrm{U} 30 \% \mathrm{wt} / \mathrm{wt}$ suspensions at three different shear rates (SR) (1.46/s, 14.6/s and 146/s) no dispersant used.

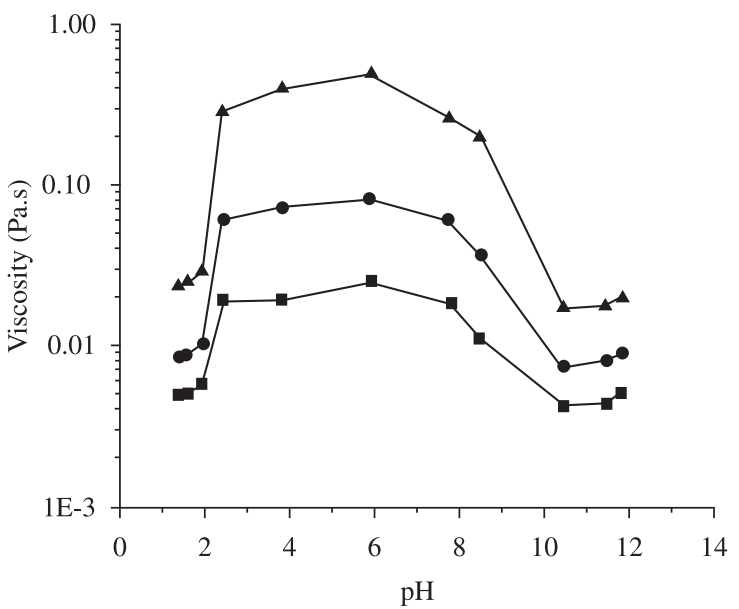

$\rightarrow$ SR $146 / \mathrm{s} \rightarrow \mathrm{SR} 14.6 / \mathrm{s} \longrightarrow \mathrm{SR} 1.46 / \mathrm{s}$

Figure 4. Viscosity as a function of $\mathrm{pH}$ of zirconia $\mathrm{Y}_{3} 30 \% \mathrm{wt} / \mathrm{wt}$ suspensions at three different shear rates (SR) (1.46/s, 14.6/s and 146/s) no dispersant used.

7.1. This difference in the viscosity in the acidic and basic conditions is probably due to the relative difference in the surface charge. At $\mathrm{pH} 7.0$ and above, the magnitude of the negative charge (electrophoretic mobility) is greater than the magnitude of the positive charge at $\mathrm{pH} 4.0$ (Figure 1). In addition, there could be some leaching out of yttrium ions from the zirconia $\mathrm{Y}_{3} \mathrm{U}$ powder. It has been shown ${ }^{7-10}$ that under acidic conditions yttrium ions are leached out from yttria stabilised zirconia powder. The leach out will increase the surface area of the powder, and make the van der Waals forces more attractive. When some species (atoms, molecules, ions etc.) are leached out from a solid body, a cavity or pore is created at that point. These cavities or pores

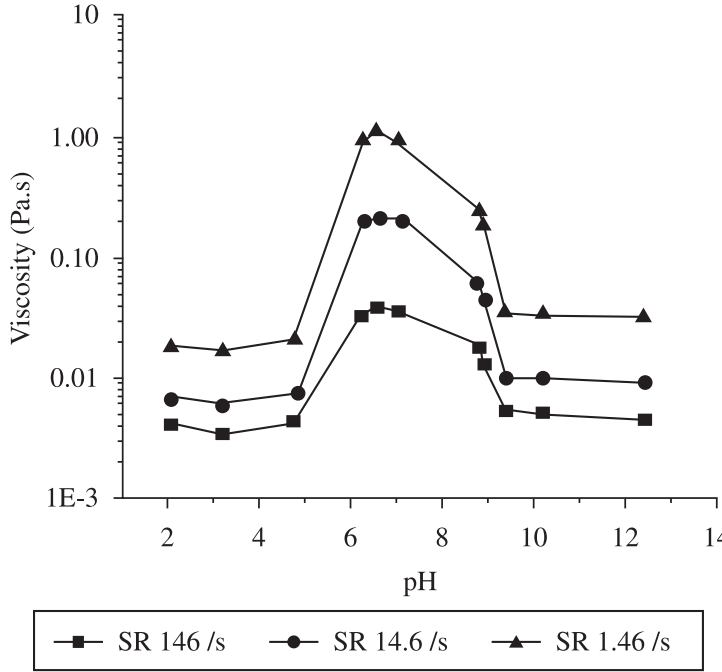

Figure 5. Viscosity as a function of $\mathrm{pH}$ of zirconia $\mathrm{ZrO}_{2} 30 \% \mathrm{wt} / \mathrm{wt}$ suspensions at three different shear rates (SR) (1.46/s, 14.6/s and 146/s) no dispersant used.

increase the surface area of the solid body from which leach out takes place.

In Figure 4 the viscosities of zirconia $\mathrm{Y}_{3} 30 \% \mathrm{wt} / \mathrm{wt}$ suspensions as a function of $\mathrm{pH}$ at three different shear rates are shown. The natural $\mathrm{pH}$ of the suspension was found to be about 8.1 . The viscosity at $\mathrm{pH}$ values of less than 2.0 and more than 10.0 are very low and the suspension is well stabilised. At $\mathrm{pH}$ values between 2.0 and 10.0 the viscosities of the suspensions are comparatively high. The highest viscosity found is at a $\mathrm{pH}$ value of circa 6.3 , and this $\mathrm{pH}$ is close to the iso-electric point (iep) of the zirconia, which is at a $\mathrm{pH}$ value 6.7. Comparing the viscosity at a $\mathrm{pH}$ of approximately 6.3 with that of a suspension of $\mathrm{Y}_{3} \mathrm{U}$ at $\mathrm{pH}$ 4.1 , at low shear rate, the viscosity of the $\mathrm{Y}_{3} \mathrm{U}$ suspension is higher than that of $\mathrm{Y}_{3}$ suspension. This difference is probably due to the difference in the surface area of the two powders. Zirconia $\mathrm{Y}_{3} \mathrm{U}$ has a BET surface area of $17.91 \mathrm{~m}^{2} \cdot \mathrm{g}^{-1}$ whereas the BET surface area of zirconia $Y_{3}$ is $8.75 \mathrm{~m}^{2} \cdot \mathrm{g}^{-1}$. The high surface area powder tends to give a higher viscosity for the suspensions of a given volume fraction.

Figure 5 depicts the results for the non-doped zirconia $\left(\mathrm{ZrO}_{2}\right)$ suspension, $30 \% \mathrm{wt} / \mathrm{wt}$, at three different shear rates. The viscosities of the suspensions are low at $\mathrm{pH}$ values of more than 9.0 and less than 5.0. The highest viscosity values peak at $\mathrm{pH}$ values between 6 and 8 , which is again in a reasonable agreement with the iep of the zirconia powder. The iep of the powder occurs at a $\mathrm{pH}$ value of 7.5. The highest viscosity of the suspension is slightly more than that of the highest viscosity of the $\mathrm{Y}_{3} \mathrm{U}$ suspension at a pH of circa 4.1 and also higher than that of the highest viscosity of $\mathrm{Y}_{3}$ suspension at a $\mathrm{pH}$ of 6.2. The BET surface area of non-doped zirconia powder is $22.5 \mathrm{~m}^{2} . \mathrm{g}^{-1}$, which is higher than that of the zirconia $\mathrm{Y}_{3}$ powder and slightly higher than the surface area of the $Y_{3} U$ powder. This difference in the viscosities of the suspensions is consistent with the differences in their surface areas. 


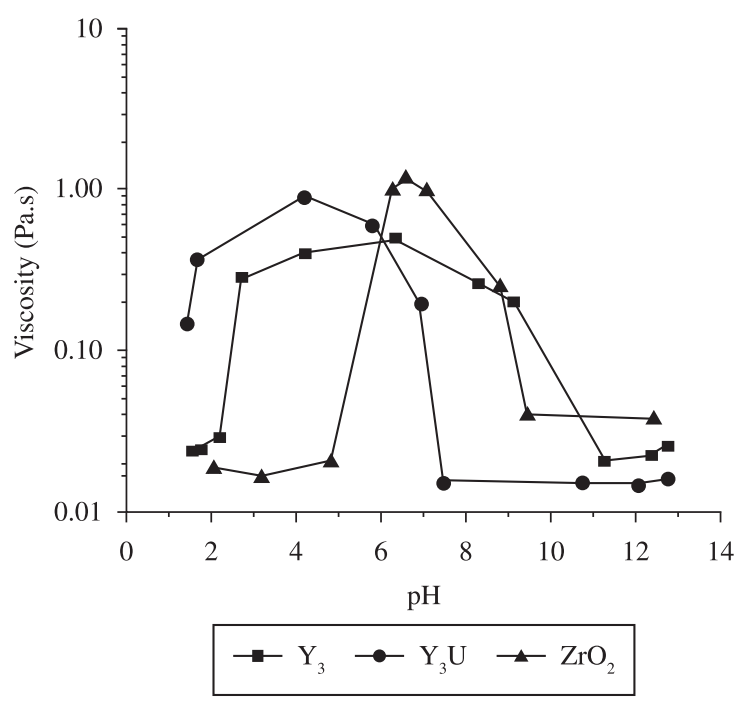

Figure 6. Viscosity as a function of $\mathrm{pH}$ for three different zirconia powders $30 \% \mathrm{wt} / \mathrm{wt}$ suspensions at a shear rate of $1.46 / \mathrm{s}$.

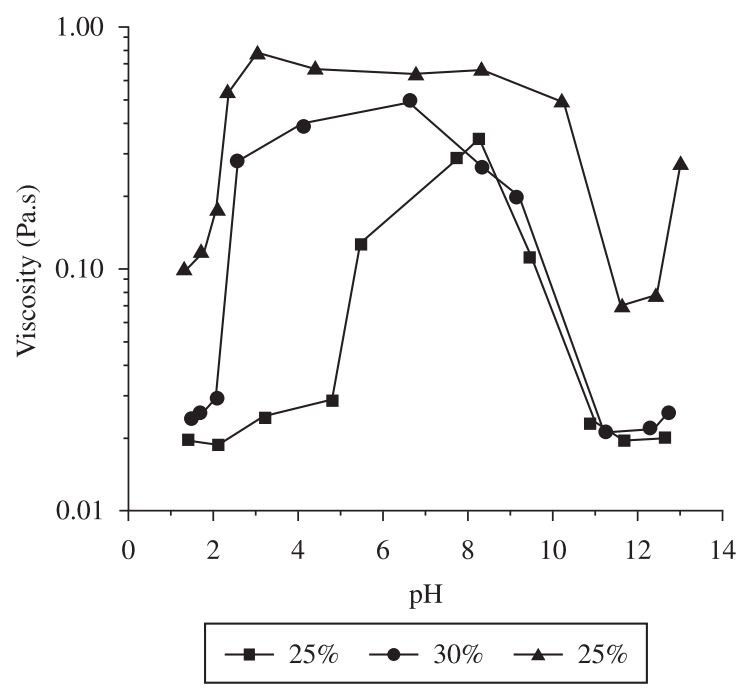

Figure 7. Viscosity as a function of $\mathrm{pH}$ for three different weight $\%$ of zirconia $\mathrm{Y}_{3}$ suspensions at a shear rate of $1.46 / \mathrm{s}$ no dispersant used.

It has been reported in the literature that the maximum viscosity and yield strength occurs near the iep, therefore the finding is in accord with the finding of other researchers ${ }^{28-30}$.

The viscosities of all the suspensions at the higher shear rates are lower when compared with the corresponding viscosities of the lower shear rates, indicating that all suspension show shear thinning behaviour which is typical of such suspensions.

In Figure 6 the viscosity data, at a shear rate of 1.46/s, as a function of $\mathrm{pH}$ of the suspensions containing $30 \mathrm{wt} / \mathrm{wt}$ of the three zirconia powders, are shown. The high viscosity region of the zirconia $\mathrm{Y}_{3}$ suspension covers from circa $\mathrm{pH} 9.0$ to $\mathrm{pH} 3.0$ and is wider than the high viscosity regimes of the zirconia $\mathrm{Y}_{3} \mathrm{U}$ and non-doped zirconia suspension. The high viscosity regions of the non-doped zirconia $\left(\mathrm{ZrO}_{2}\right)$ and zirconia $\mathrm{Y}_{3} \mathrm{U}$ suspensions are from $\mathrm{pH}$ values 9.0 to 6.0 and $\mathrm{pH}$ values 7.0 to 2.0 , respectively.

\subsubsection{Effect of solid content}

The effect of the variation of the solid content as a function of $\mathrm{pH}$ on the zirconia $\mathrm{Y}_{3}$ suspensions was also investigated. In Figure 7, the viscosity against the $\mathrm{pH}$ for the three different solid content suspensions of zirconia $\mathrm{Y}_{3}$ at shear rate of $1.46 / \mathrm{s}$ are shown. From the figure it can be seen that, as the solid content of the suspension is increased, the "stability region", that is the $\mathrm{pH}$ range which gives the low viscosity, decreases. When the solid content of the suspensions is $25 \% \mathrm{wt} / \mathrm{wt}$, the suspensions have low viscosities in the $\mathrm{pH}$ range of more than 11.0 to less than 5.0. However, when the solid content is increased to $35 \%$ $\mathrm{wt} / \mathrm{wt}$ the acidic region of the low viscosity shifts to a $\mathrm{pH}$ of circa 2.0 and less. The extreme $\mathrm{pH}$ conditions, especially the high acidic $\mathrm{pH}$ values, are not suitable from the processing view point and have deleterious effects on the quality of the suspensions as well as on the products. This narrowing of the stability region, using $\mathrm{pH}$ adjustment, serves to indicates that it is not possible to produce high solids loading suspensions using $\mathrm{pH}$ control alone. It has also been observed that the $\mathrm{pH}$ of the acidic suspensions increases with time and this effect is more pronounced at the higher volume fractions and under the more extreme acidic conditions.

The suspensions whose results are reported in Figure 3 to Figure 7 were stable in the absence of any dispersant. The stability of these suspensions was checked by the rheological measurement over a period of one week. During this period (one week), no significant difference in the viscosity was observed. If the suspensions were unstable the viscosity would change (increase) with the passage of time. Therefore, it can be concluded that these system are stable.

\section{Conclusions}

The rheology of the zirconia powders studied is found to be affected by the change in the ambient $\mathrm{pH}$ of the suspension. The $\mathrm{pH}$ changes essentially modify the surface charge which in turn controls the interparticle interactions. At the $\mathrm{pH}$ where the effective potential (the zeta-potential) on the particles is zero, called the isoelectric point (iep), the viscosity is high and as the $\mathrm{pH}$ changes away from the iep the viscosity decreases. This is due to the fact that at the iep the van der Waals attractive forces dominate and aggregation of the particles occurs. At $\mathrm{pH}$ values away from the iep the electrostatic repulsion of the particle/double layers stabilises the suspension and hence prevents the particles coming close to each other and agglomerating. As a result the viscosity of the suspensions is lower.

The particle size, the size distribution and the surface area of the particles also plays an important part in the rheology as was observed in the case of the non-doped zirconia and 3 mole $\%$ yttria stabilised zirconia powders. The finer particles and the particles having higher surface area tend to give higher viscosities under similar surface charge conditions. Increasing the solid content decreases the extent of stable region and increases the low optimum viscosity values. 


\section{References}

1. Porter DL and Heuer AH. Mechanisms of Toughening Partially Stabilized Zirconia (PSZ). Journal of American Ceramic Society. 1977; 60:183-184. http://dx.doi.org/10.1111/j.1151-2916.1977. tb15509.x

2. Massaki T. Mechanical properties of toughened $\mathrm{ZrO} 2-\mathrm{Y} 2 \mathrm{O} 3$ Ceramics. Journal of American Ceramic Society. 1986; 69:638640. http://dx.doi.org/10.1111/j.1151-2916.1986.tb04823.x

3. Lewis JA. Colloidal processing of ceramics. Journal of American Ceramic Society. 2000; 83:2341-2359. http://dx.doi. org/10.1111/j.1151-2916.2000.tb01560.x

4. Ferreira JMF and Diz HMM. Effect of solids loading on slip casting performance of silicon carbide slurries. Journal of American Ceramic Society. 1999; 82:1993-2000. http://dx.doi. org/10.1111/j.1151-2916.1999.tb02031.x

5. Reed JS. Principles of Ceramic Processing. 2th ed. New York: John Wiley and Sons; 1995.

6. Moreno R. The role of slip additives in tape casting technology: Part 1-solvents and dispersants. American Ceramic Society Bulletin. 1992; 71:1521-1531.

7. Bergstrom L, Shinozaki K, Tomiyma H, and Mizutani N. Colloidal processing of a very fine $\mathrm{BaTiO} 3$ powder, effect of particle interactions on the suspension properties, consolidation and sintering behavior. Journal of American Ceramic Society. 1997; 80:291-300. http://dx.doi.org/10.1111/j.1151-2916.1997. tb02829.x

8. Mistler RE and Twiname ER. Tape Casting, Theory and Practice. Westerville: The American Ceramic Society; 2000.

9. Lange FF. Powder Processing Science and Technology for Increased Reliability. Journal of American Ceramic Society. 1989; 72:3-15. http://dx.doi.org/10.1111/j.1151-2916.1989. tb05945.x

10. Plucknett KP, Caceres CH and Wilkinson DS. Tape Casting of Fine Alumina/Zirconia Powders for Composite Fabrication. Journal of American Ceramic Society. 1994; 77:2137-2144. http://dx.doi.org/10.1111/j.1151-2916.1994.tb07109.x

11. Russell WB, Saville DA and Schowalter WR. Colloidal Dispersion. Cambridge: Cambridge University Press; 1989. $258 \mathrm{p}$.

12. Hunter RJ. Foundations of Colloid Science. Oxford Science; 1991. vol. 1.

13. Napper DH. Polymeric stabilisation of colloidal dispersions. New York: Academic Press; 1983.

14. Everett DH. Basic principles of colloids. London: Royal Society of Chemistry; 1989.

15. Fleer GH, Cohen Sturat MA, Scheutjens JMHM, Cosgrove $\mathrm{T}$ and Vincent B. Polymer at Interfaces. London: Chapman and Hall; 1993.

16. Briscoe BJ, Khan AU and Luckham PF. stabilising zirconia aqueous suspensions using commercial polyvalent electrolyte solutions. Journal of European Ceramic Society. 1998; 18:21692173. http://dx.doi.org/10.1016/S0955-2219(98)00148-4

17. Leong YK and Boger DV. surface chemistry and rheological properties of zirconia suspensions. Journal of Rheology. 1991; 35:149-165. http://dx.doi.org/10.1122/1.550225

18. Guo J, Tiu C, Uhlherr PHT and Fang T-N. yielding behavior of organically treated anatase $\mathrm{TiO} 2$ suspension. Korea-Australia Rheology Journal, 2003; 9-17:15.

19. Hsu J-P and Nacu A. an experimental study of the rheological properties of aqueous ceria dispersions. Journal of Colloid and Interface Science. 2004; 274:277-284. http://dx.doi. org/10.1016/j.jcis.2004.02.063

20. Wanga YH, Liu XQ and Menga GY. dispersion and stability of $8 \mathrm{~mol}$ \% yttria stabilized zirconia suspensions for dip-coating filtration membranes. Ceramics International. 2007; 33:10251031. http://dx.doi.org/10.1016/j.ceramint.2006.03.011

21. Shaw DJ. Colloid and Surface Chemistry. 4th ed. Oxford: Butterworth-Heinemann; 1992.

22. Hunter RJ. Zeta Potential in Colloidal Science. Academic Press Ltd; 1981. p. 278-279.

23. Healy TW and White LR. geochemical modeling of waterrock interactions using SOLMINEQ.88. Advances in Colloid and Interface Science. 1978; 9:303-345. http://dx.doi. org/10.1016/0001-8686(78)85002-7

24. Davis JA and Leckie JO. surface ionization and complexation at the oxide/water interface II. surface properties of amorphous iron oxyhydroxide and adsorption of metal ions. Journal of Colloid and Interface Science. 1978; 67:90-107. http://dx.doi. org/10.1016/0021-9797(78)90217-5

25. Yates DE, Levine S and Healy TW. Journal of Chemical Society Faraday Transaction I. 1974; 70:1807. http://dx.doi. org/10.1039/f19747001807

26. Pugh RJ and Bergstrom L. Surface and Colloid Chemistry in advance ceramic processing. New York: Marcel Dekker; 1994.

27. Shojai F, Pettersson ABA, Mäntylä $T$ and Rosenholm JB. electrostatic and electrosteric stabilization of aqueous slips of $3 \mathrm{Y}-\mathrm{ZrO} 2$ powder. Journal of European Ceramic Society. 2000; 20:277-283. http://dx.doi.org/10.1016/S0955-2219(99)00173-9

28. Leong YK and Boger DV. surface chemistry and rheological properties of zirconia suspensions. Journal of Rheology. 1991; 35:149-165. http://dx.doi.org/10.1122/1.550225

29. Guo J, Tiu C, Uhlherr PHT and Fang T-N. yielding behavior of organically treated anatase $\mathrm{TiO} 2$ suspension. Korea-Australia Rheology Journal, 2003; 15:9-17.

30. Hsu J-P and Nacu A. An experimental study of the rheological properties of aqueous ceria dispersions. Journal of Colloid and Interface Science. 2004; 274:277-284. http://dx.doi. org/10.1016/j.jcis.2004.02.063 